\title{
Teknik Eleman Yetiştirmede Eğitim Şartlarının Öğrenciler Üzerindeki Etkilerinin İncelenmesi*
}

\author{
Güllü Akkaş ${ }^{1 * *}$, Feyza Gürbüz ${ }^{2}$ \\ ${ }^{1}$ Kayseri Üniversitesi, Meslek Yüksekokulu, Makine ve Metal Teknolojileri Bölümü, Kayseri, Türkiye (ORCID: 0000-0001-7836-9746) \\ ${ }^{2}$ Erciyes Üniversitesi, Mühendislik Fakültesi, Endüstri Mühendisliği Bölümü, Kayseri, Türkiye (ORCID: 0000-0002-6327-8232)
}

((Konferans Tarihi: 5-7 Mart 2020)

(DOI: 10.31590/ejosat.)

ATIF/REFERENCE: Akkaş, G., \& Gürbüz, F.. (2020). Teknik Eleman Yetiştirmede Eğitim Şartlarının Öğrenciler Üzerindeki Etkilerinin İncelenmesi. Avrupa Bilim ve Teknoloji Dergisi, (Özel Sayı), 197-203.

$\ddot{O} \mathbf{z}$

Mesleki eğitimde öğrenci beklenti ve memnuniyeti her zaman merak edilen ve araştırılan konular olmuştur. Toplumlardaki sanayileşme süreci her zaman nitelikli teknik eleman ihtiyacını yanında getirmiştir. Meslek yüksekokulları (MYO) endüstri için nitelikli teknik eleman yetiştirme kaynağının başında gelmektedir. Bu çalışma MYO öğrencilerinin beklenti ve memnuniyetlerinin demografik yapıya göre değişimini araştırmıştır. Öğrencilerin beklentilerini ve memnuniyetini ölçmek için Google forms üzerinden çeşitli başlıklar altında anket yapılmıştır. Anket sonuçları istatistiksel olarak ve veri madenciliği teknikleri kullanılarak değerlendirilmiş ve öğrencilerin genel anlamda kaygılandığı durumlar ve memnuniyet duydukları konu başlıkları belirlenmiştir.

\section{Investigation of the Effects of Educational Conditions on Technical Staff Training on Students}

\begin{abstract}
Student expectations and satisfaction in vocational education have always been curious and researched topics. The industrialization process in societies always brought the need for qualified technical staff. Vocational schools (Vocational Schools) are the primary source of training qualified technical staff for the industry. This study investigated the changes and expectations of Vocational School students according to the demographic structure. In order to measure the expectations and satisfaction of students, a questionnaire was conducted under various headings on Google forms. The results of the survey were evaluated statistically and by using data mining techniques, and the situations in which students were generally concerned and the topics they were satisfied were determined.
\end{abstract}

Keywords: Vocational Education, Statistical Analysis, Data Mining

\footnotetext{
${ }^{*}$ Bu makale International Conference on Access to Recent Advances in Engineering and Digitalization (ARACONF 2020) de sunulmuştur.

** Sorumlu Yazar: Kayser,Üniversitesi, Meslek Yüksekokulu, Makine ve Metal Teknolojileri Bölümü, Kayseri, Türkiye, ORCID: 0000-0001-78369746, gullu.akkas@kayseri.edu.tr
} 


\section{Giriş}

Mesleki eğitim ve öğretim son ylllarda iki ana nedenden ötürü bir canlanma yaşadı. İlk olarak, ekonomik büyümeyi teşvik etmenin uygun bir yolu olarak. İkinci olarak, sosyal gelişimi teşvik etmek için potansiyel olarak güçlü bir araç olarak görülmektedir. (Nillson, 2010) Bu nedenle mesleki eğitim veren kuruluşlara öğrenci çekebilmek önem arz etmektedir.

Binici ve Arı, Mesleki ve Teknik eğitimde arayışlar isimli çalışmalarında mesleki eğitimimizde reformlara ihtiyaç duyulduğunu savunmuşlardır (Arı \& Binici, 2004). Gizir ve Demir yaptıkları çalışmalarda, bireysel farklılıkları dikkate alan ve öğrenci-odaklı bir felsefeyle öğrencilerin, ilgi, beceri ve ihtiyaçlarını gözeten programların tüm eğitim kurumlarında geliştirilmesi gerekliliğini savunmuşlardır (Gizir, 2014) (Demir, 1996). Öğrenci odaklı yaklaşımda, öğrenci beklentileri ve memnuniyetleri büyük bir yere sahiptir, çünkü üniversite sınavlarındaki seçimleri doğrudan etkilemektedir.

Son yıllarda ülkemizde kurulan üniversite sayısı artmıştır. 2019 yılı itibariyle 129 devlet ve 73 vakıf üniversitesi eğitim hayatına devam etmektedir (YÖK İ. V., 2020). Artan üniversite sayısına bağlı olarak öğrencilerin seçim kriterleri değişmiştir. Buna bağlı olarak öğrencinin seçmediği bölümler ortaya çıkmışıı. Meslek Yüksek Okulları (MYO) bu tehlikelerle karşılaşan eğitim kurumları içerisindedir. Özellikle MYO'ların sanayi bölgelerinde kurulmasına yönelik YÖK'ün teşvikleri görülmektedir ve bu teşvikler çerçevesinde MYO'ların sanayi bölgesinde kurulmakta olduğu uygulamalar yaygınlaşmıştır (YÖK, 2020).

Veri madenciliği farklı alanlarda başarıyla uygulanmaktadır. Eğitim sektörü de bu uygulamaların yapılabileceği alanlardan biridir. $\mathrm{Bu}$ çalışmada Kayseri üniversitesi bünyesindeki MYO öğrencilerinin demografik yapıları incelenmiştir. Üniversiteye gelmeden önceki beklentilerinin ne olduğu, geldikten sonraki memnuniyet seviyeleriyle anketler yardımıyla kıyaslanmıştır. MYO'larının şehir içerisindeki konumları ile ilgili beklentileri ve mevcut durumdan memnuniyetleri ölçülmüştür. Anketler veri madenciliği yöntemi ile anlamlı hale getirilmiştir.

Nilsson "mesleki eğitim ve öğretim ekonomik büyüme için bir motor ve sosyal içerme aracı mı" isimli çalışmasında mesleki eğitimin varsayılan etkileri alandaki genişleyen literatür temelinde eleştirel olarak incelemiş̧ir (Nillson, 2010).

Kılıç ve Kuyumcu; Teknik Eğitim Fakültesi Öğrencilerinin Gelecekten Beklentileri isimli çalı̧̧malarında Teknik Eğitim Fakültesi'nde okuyan öğrencilerin mezun olduktan sonraki beklentilerini belirlemek üzerine çalışmışlardır (Kılıç \& Kuyumcu, 2008). 2001).

Giorgio Brunello, 13 Avrupa ülkesinde eğitim ve öğretim arasındaki tamamlayıcılığın deneysel çalışmasını yapmıştır (Brunello,

Ucar ve Sen, uzaktan Bilgisayar mühendisliği bölümü uzaktan eğitim öğrencilerinin başarılarının veri madenciliği yöntemleri ile değerlendirilmesi isimli çalışmada Karabük’teki Bilgisayar mühendisliği öğrencilerinin başarılarını veri madenciliği tekniklerini kullanarak karşıllaştırmışlardır (Sen \& Ucar, 2012).

Veri önişleme veya hazırlama, veri madenciliği sürecinde önemli ve kritik bir adımdır ve bir veri madenciliği projesinin başarısı üzerinde büyük bir etkiye sahiptir (Hu, 2003). Çeşitli veri kaynaklarında ve web'de birçok düşük kaliteli bilgi mevcut olsa da, birçok kuruluş veya şirket, verilerin yüksek kâr amaçlı kullanılabilecek temiz formlara nasıl dönüştürüleceğiyle ilgilenmektedir. Bu hedef, ham verilerin temizlenmesini amaçlayan veri analizine acil ihtiyaç duymaktadır (Zhang, Zhang, \& Yang, 2003).

Chen, Tseng ve Hong (2008), belirli bir veri kümesinin dizinlerini temsil eden en küçük özellik kümesini bulmak için bit tabanlı bir özellik seçim yöntemi önermektedir. (Chen, Tseng , \& Hong, 2008).

Gürbüz, Özbakır ve Yapıcı'nın çalışmalarında veri kümesini azaltmak amacıyla analiz, anomali tespit analizi, buluntu bağımlılıkları ve kaba kümeler kullanılmıştır. Ayrıca, veri madenciliğinin sınıflandırma teknikleri, bileşenin sınıf niteliği olarak uyarı seviyesini tahmin etmek için kullanılır (Gürbüz, Özbakır, \& Yapıcı, 2011).

\section{Materyal ve Metot}

Bu çalışmada Kayseri Üniversitesi Meslek Yüksekokulu öğrencilerinin üniversite tercihinden önceki beklentileri ile ilgili ve tercih ettikleri bölümden memnuniyetleri ile ilgili ve ek olarak öğrencilerin demografik yapısı ile ilgili sorular yöneltilmiştir.

Birinci bölümde öğrenciler demografik yapıyla ilgili soruları cevaplamıştır. Bu sorular öğrencilerin bölümleri, programları, cinsiyetleri, yaşları, sınıfları, aile gelir düzeyleri, anne ve baba eğitim durumları, anne-baba meslekleri, öğrencilerin kardeş sayısı gibi konularda fikir vermektedir.

İkinci bölümün soruları ise sekiz ana başlıktan oluşmuştur ve üniversite öğrencisi olmadan önce bir üniversiteden beklentilerini ölçmeye yöneliktir. Bu bölümün ana başlıkları şöyledir:

1. Akademik olanaklar ve öğrenmeyi destekleyici olanaklar hakkındaki beklentiler

2. Üniversitenin sportif faaliyetleri hakkındaki beklentileri

3. Meslek Yüksekokullarının yerleşimi hakkındaki beklentileri

4. Meslek Yüksekokullarından mezun olduktan sonraki olası iş potansiyeli ile ilgili beklentileri

5. Öğrencilere sağlanan hizmetler ile ilgili beklentileri 
6. Eğitim programları ve öğretim ile ilgili beklentileri

7. Ölçme ve değerlendirme sistemi hakkındaki beklentileri

8. Akademik danışmanlık ve rehberlik hakkındaki beklentileri

Üçüncü bölümde de yedi ana başlık altında öğrencilerin mevcut durumdan memnuniyetleri ölçülmüştür. Son olarak öğrencileri mevcut durumlarında en çok memnun eden ve en çok mutsuz eden detaylar hakkında fikir alınarak anket tamamlanmışır. Bu bölümün soruları için ana başlıklar ise aşağıdaki gibidir.

1. Akademik olanaklar ve öğrenmeyi destekleyici olanaklar hakkındaki memnuniyetleri

2. Üniversitenin sportif faaliyetleri hakkındaki memnuniyetleri

3. Meslek Yüksekokullarının yerleşimi hakkındaki memnuniyetleri

4. Öğrencilere sağlanan hizmetler ile ilgili memnuniyetleri

5. Eğitim programları ve öğretim ile ilgili memnuniyetleri

6. Ölçme ve değerlendirme sistemi hakkındaki memnuniyetleri

7. Akademik danışmanlık ve rehberlik hakkındaki memnuniyetleri

Yapılan anketlerden elde edilen veriler PolyAnalyst 5.0 programı ile işlenmiştir. Bu program serbest metin yığınları ve yapılandırılmış veri yığınlarında gizlenmiş, işlenebilir bilgilerin çıkarılabilmesi için önde gelen bir sistemdir. Programda tüm veri kaynaklarına erişilebilir ve farklı kaynaklardan gelen veriler birleştirilebilir. Eksik verileri çarpıtma ve yazım hatalarını düzeltme gibi güçlü veri temizleme işlemleri ile kirli veriler şekillendirilebilir. Çeşitli ileri düzey doğal dil işleme araçlarıyla tamamlanan çok çeşitli istatistiksel ve makine öğrenimi algoritmaları arasından seçim yapılabilmektedir (Megaputer, 2020).

Anket değerlendirme sürecinde programın hem istatistiksel analiz, hem de metin analiz motoru kullanılmıştır. Metin Analizi (TA) arama motoru, yapılandırılmamış metin notlarının veritabanı biçiminde morfolojik ve anlamsal analizini yapar. TA, metin notlarından en önemli kelimeleri ve kelime kombinasyonlarını çıkarır ve sayar ve veri tabanı kayıtlarını karşılaşılan terimlerin kalıplarıyla tokenize etmek için terim kurallarını saklar. TA tarafindan elde edilen sonuçlar, PolyAnalyst'in diğer görselleştirme (LA) ve sınıflandırma (DT, DF) motorlarına girdi olarak kullanılabilir. İstatistikler bir makine öğrenme algoritması değildir, ancak yine de analiz prosedürünün hayati bir parçasıdır. Özet İstatistik arama motoru, ortalamalar, standart sapmalar ve frekanslar dahil olmak üzere verilerinizle ilgili temel istatistikleri sağlar. Ek olarak, Özet İstatistikler raporu her kategori, dize ve evet / hayır değişkeni için frekans grafikleri içerir (PolyAnalyst, 2007).

\section{Araştırma Sonuçları ve Tartışma}

Anketin birinci bölümünde MYO öğrencilerine aileleri hakkında sorular yöneltilmiştir. Buna göre öğrencilerin aile gelir düzeyi genel olarak 2000-4000 TL aralığında ve 2000TL 'nin altında olduğu tespit edilmiştir. Aile gelir düzeyi 4000 TL'nin üzerinde olan öğrencilerin MYO’ları tercih etme durumu azınlıktadır (Şekil 1)

Anne ve baba eğitim durumları incelendiğinde, çoğunlukla ilkokul ve lise düzeyinde ebeveynlerin çocuklarının MYO’lara yöneldiği söylenebilir. Yüksek oranda ev hanımı annelerin çocukları tercihini MYO'ya yöneltmiştir.

Babaların mesleğinin ise çoğunlukla emekli, çiftçi, serbest meslek, işçi ve esnaf olduğu görülmüştür (Şekil 2). Bu meslek gruplarına nispeten MYO’ya çocuğunu en az yönlendiren babaların mesleklerinin öğretmen ve muhasebeci olduğu söylenebilir. Elde edilen sonuçlarda öğrenci profilinin daha çok aile bütünlüğünün sağlanmış olduğu, yani anne babanın sağ olduğu veli gruplarının çocukları MYO'ları tercih etmiş̧tir. Öğrencilerin kardeş sayıları ortalama 3'tür ve üst seviyede 9 kardeşe kadar çıkmaktadır.

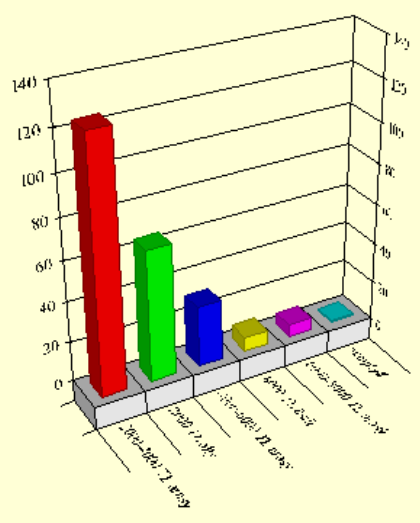



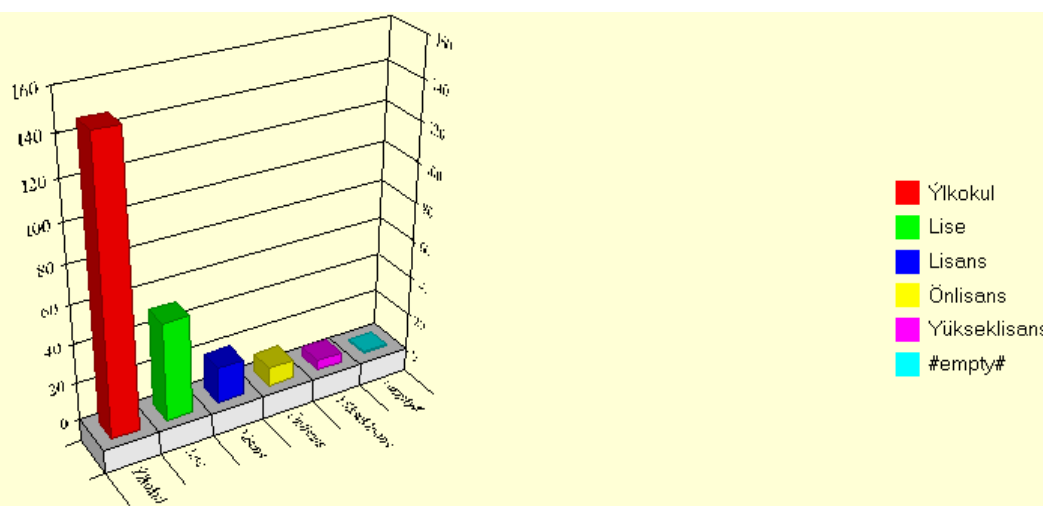

\section{Şekil 2. Öğrencilerinin babalarının eğitim durumu}

Yapılan anketlerin değerlendirilmesi sonucunda ikinci bölümünde yer alan verilere göre öğrencilerin beklenti ve memnuniyetleri tespit edilmiş̧ir.

Öğrenci beklenti ve memnuniyetleri 8 ana başlı altında incelenmiştir. İlk olarak Akademik olanaklar ve öğrenmeyi destekleyici olanaklar hakkındaki beklentiler ile ilgili sorular öğrencilere yöneltilmiş bu kısımda öğrenci beklentisinin yüksek olduğu ölçülmüştür. Bu kısımda çoğu öğrenci yönetimden ve idari personelden aldıkları davranış duyarlılığını önemserken, kulüp etkinlikleri, kültürel ve sanatsal faaliyet gibi etkinlikleri geri plana almışlardır. Ancak kendileri için öncelemiş oldukları davranış ve tutum beklentilerinden memnuniyetleri şekil 3’te görüldüğü gibi orta düzeyde ve ortanın biraz üstünde çıkmıştır. Bunların yanı sıra sağlık hizmetlerinin kaliteli olmasının kendileri için önemli olduğunu düşünmekteler (Şekil 3 ve Şekil 4).

Beklentiler

Şekil 3 Yönetimin öğrenci sorunlarına karşı duyarlllı̆̆ ile ilgili beklentiler ve memnuniyetleri

Beklentiler

Şekil 4 Öğrenci klüpleri ile ilgili beklentilerin önem slrası (1 önemsiz-5 çok önemli) ve mevcut durumdan memnuniyetleri

Bir diğer başlıkta ise MYO'nun şehir içerisindeki konumu hakkındaki beklentileri ölçülmüştür. Öğrenci gruplarının eğitim gördükleri binanın konumunun sanayi bölgesinde olmasını istemedikleri görülmüştür. Daha çok okulun şehir merkezinde ve özellikle merkez kampüs içerisinde bulunmasını istemektedirler (Şekil 5, Şekil 6 ve Şekil 7). 


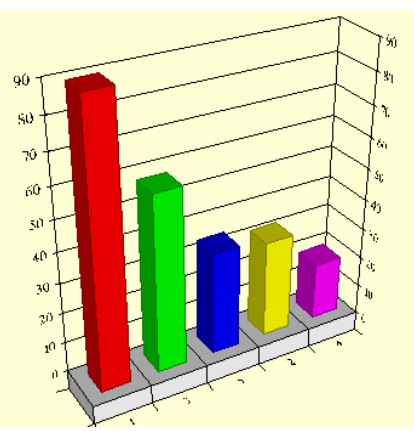

Şekil 5. MYO ların sanayi bölgesinde bulunması ile ilgili beklentileri
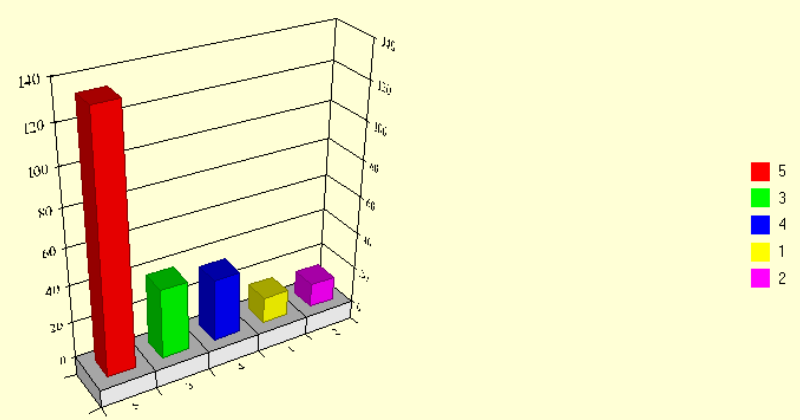

Şekil 6. MYO’ların şehir merkezine yakın olması gerekliliği ile ilgili beklentileri

Başka bir başlık ise öğrencilerin Meslek Yüksekokullarından mezun olduktan sonraki olası iş potansiyeli ile ilgili beklentilerini ölçmeye yöneliktir (Şekil 7 ve Şekil 8). Bu kısımda öğrenciler sanayi bölgesinde çalışıp çalışmayacaklarından çoğunluk olarak emin değiller, ancak çalışabileceğine de inanan bir çoğunluk var. Öğrencilerin mezun oldukları alan ile ilgili bir sektörde çalışabileceklerine olan inançları yüksektir.
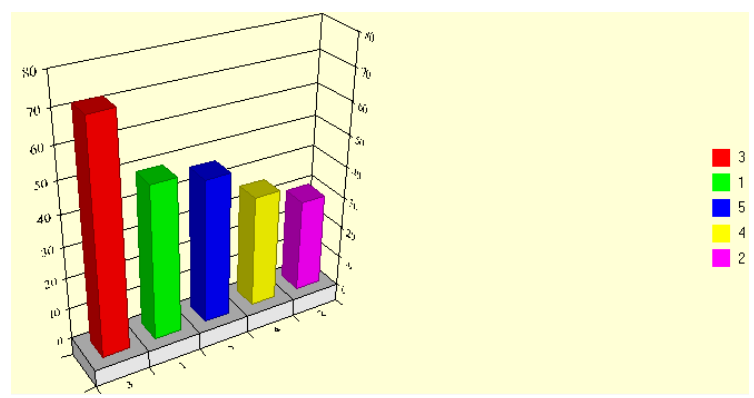

Şekil 7. Sanayi bölgesinde iş bulabilme ile ilgili beklentileri

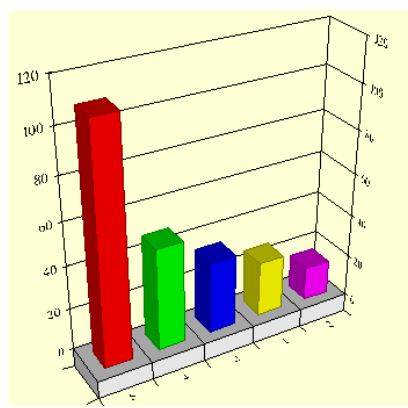

Şekil 8. Mezun oldukları alan ile ilgili çalışabilecekleri hakkındaki beklentileri

Anketi beklenti olarak ele aldığımızda öğrencilerin okulun fiziksel ortamının (yemekler, yemek fiyatları, tuvalet, lavabo yeterliliği, dersliklerin temizliği, aydınlatılması, ısınması gibi) kalitesinden, kütüphane, kantin ve burs gibi hizmetlerden yana beklentilerinin yüksek olduğu sonucuna ulaşılmıştır. Bu alandaki memnuniyetlerine bakıldığında ise genel olarak orta derecede fiziki şartlar, kantin ve burs konularından memnun oldukları söylenebilir. 
Anketi Eğitim programları ve öğretim ile ilgili beklentiler, Ölçme ve değerlendirme sistemi hakkındaki beklentiler, Akademik danışmanlık ve rehberlik hakkındaki beklentiler olarak ele aldığımızda beklentilerin yüksek olduğu görülmektedir. Bunların yanı sıra bu konularda memnuniyet düzeyinin genelde orta seviyede kaldığı söylenebilir.

Sunulan imkanlar içerisinde en çok memnununum cevabını alan seçenek bilgisayar imkanları iken, çoğunluğun memnun kalmadığ1 konuların ise kulüp imkanları, sanatsal faaliyetler, sportif faaliyetler, külttürel etkinlikler ve sağlık hizmetleri olduğu görülmüştür (Şekil 9=EK1).

Anketimizde yer alan son üç soruya verilen cevaplara uygulanan metin analizi sonucunda öğrencilerin genel olarak hem fikir oldukları yüksekokullarında onları en çok mutlu eden üç neden içerisine sırasıyla arkadaşları, hocaları ve okul ortamı gelmekte iken, en çok mutsuz eden 3 neden uygulamaların yetersiz olması, sosyal tesis yetersizliği, kantin ve lavabo temizliği gelmektedir.

En çok öneri alan konular ise uygulama çalışmalarının ve sosyal etkinliklerin artırılması olarak tespit edilmiştir. Yabancı dil eğitimini ise yetersiz bulmaktadırlar.

\section{Sonuç}

Birinci bölümde öğrenciler demografik yapıyla ilgili soruları cevaplamıştır. Bu sorular öğrencilerin bölümleri, programları, cinsiyetleri, yaşları, sınıfları, aile gelir düzeyleri, anne ve baba eğitim durumları, anne-baba meslekleri, öğrencilerin kardeş sayısı gibi konularda fikir vermektedir.

Anket sonuçlarına göre öğrencilerin ailelerinin sosyo-ekonomik ve sosyo-kültürel profilinin düşük olduğu gözlemlenmiştir.

Nitelikli eleman yetiştirmede kaliteyi yukarı seviyeye çıkarmak için sosyo-ekonomik ve sosyo-kültürel profilleri yüksek ailelerin çocuklarının da bu alana yönlendirebilecek düzeyde çalışmaların yapılması esastır.

İkinci ve üçüncü bölümlerin soruları ise sekiz ana başlıktan oluşmuştur ve üniversite öğrencisi olmadan önce bir üniversiteden beklentilerini ve öğrencilik süreçlerindeki durumdan memnuniyetlerini ölçmeye yöneliktir. Bu bölümün ana başlıkları ve bunlar hakkındaki öneriler aşağıda özetlenmiştir.

Akademik olanaklar ve öğrenmeyi destekleyici olanaklar hakkındaki beklentileri yapılan anketler sonucunda yüksek çıkmıştır. Ancak memnuniyet seviyesi orta ve ortanın altında çıkmıştır. Burada kalite sistemlerinin çalışmaları üzerinde yoğunlaşarak öğrenci anketleri ile yönetimin kendi iç paydaşları içerisindeki konumunu iç değerlendirmeye tabi tutarak gerekli revizyonları yapması uygun olacaktır.

Üniversitenin sportif faaliyetleri hakkındaki beklentileri orta seviyelerde kalmakta ancak sosyo-ekonomik ve soyso-kültürel açıdan yüksek profilde veli ve öğrenciyi MYO’lara çekmek de gerekmektedir. Bunun için öğrenciye yönelik sportif faaliyetleri (ilgili spor takımlarının kurulması, turnuvalarda yer almak... gibi) artırmak ve medyada bunlarla anılabilmek etkili olacaktır.

Meslek Yüksekokullarının yerleşimi hakkındaki beklentileri, Yüksek Öğretim Kurumu'nun (YÖK) devlet desteği MYO'ların sanayi bölgesinde kurulmasına yönelik olsa da, öğrenci odaklı yaklaşım ele alındığında öğrencilerin merkezde olan MYO'ları tercih etme eğiliminde olduğu tespit edilmiştir. Bu anlamda mevcut konumlarından memnun oldukları ve sanayi bölgesinde bir MYO'nu düşünmeyecekleri belirlenmiş̧ir. $\mathrm{Bu}$ anlamda YÖK desteklerinin MYO'ların konumundan çok teknik alt yapılarını geliştirmeye yönelik kaynaklara kanalize etmesi tavsiye edilebilir.

Meslek Yüksekokullarından öğrencilerin mezun olduktan sonraki iş bulma konusundaki beklentileri kendi alanları ile ilgili çalışma imkânı bulabilecekleri yönündedir. Bu beklentiyi desteklemek adına MYO yönetimlerinin sanayi ile iş birliği içerinde kalması gerekmektedir.

Öğrencilere să̆lanan hizmetlerde öğrencilerin daha hassas olduğu anket sonuçlarından çıkarılmıştır. Bu yönde alınacak tedbirler MYO’larda hizmet alt yapılarını güçlendirerek öğrenci memnuniyetini artırmak olacaktır.

Öğrencilerin en çok beklenti içerisinde bulundukları konuların başında eğitim programları ve öğretim ile ilgili beklentiler gelmektedir. Bu konuda memnuniyetleri ortanın üzerindedir. Bu sonuca göre öğrencilerin bilinçli bir şekilde meslek eğitimi almak için MYO’ları tercih etmekte olduğu söylenebilir.

$\mathrm{Bu}$ anketler göstermektedir ki, MYO’larda akreditasyon çalışmaları daha üst seviyede öğrencileri çekmek ve mevcut öğrenci sayılarını koruyabilmek açısından ciddiye alınması gereken konulardır.

İleriki çalışmalarda anket kapsamının genişletilerek çok daha fazla MYO öğrencisine ulaşılması ve mezun takip sistemleri ile daha fazla mezuna ulaşılması hedeflenmektedir.

\section{Kaynakça}

Arı, N., \& Binici, H. (2004). Mesleki ve Teknik Eğitimde Arayışlar. GÜ. Gazi Eğitim Fakültesi Dergisi, Cilt 24, Sayı 3, pp. 383-396. Brunello, G. (2001). On the Complementarity between education and training in Europe. IZA Discussion Paper, No.309,FEEMWorkingPaperNo.40.AvailableatSSRN: https://ssrn.com/abstract=273040 or http://dx.doi.org/10.2139/ssrn.273040 June 2001. 
Chen, W., Tseng, S., \& Hong, T. (2008). An efficient bit-based feature selection method. Expert Systems with Applications, Vol. 34, pp. 2858-2869.

Demir, A. (1996). Üniversitedeki seçmeli ders uygulamasının öğrenciler ve öğretim üyelerince değerlendirilmesi. Psikolojik Danışma ve Rehberlik Dergisi, Vol 2, pp 24-31.

Gizir, C. (2014). Orta Doğu Teknik Üniversitesi Son Sınıf Öğrencilerinin Problemleri Üzerine Bir Çalışma. Mersin Üniversitesi Eğitim Fakültesi Dergisi, cilt 1, sayı 2.

Gürbüz, F., Özbakır, L., \& Yapıc1, H. (2011). Data mining and preprocessing application on component reports of an airline company in Turkey. Expert System with Applications, vol 38, pp. 6618-6626.

$\mathrm{Hu}, \mathrm{X}$. (2003). DB-reduction: A data preprocessing algorithm for data mining applications. Applied Mathematics Letters, Vol.16, pp.889-895.

Kılıç, A., \& Kuyumcu, A. (2008). Teknik Eğitim Fakültesi Öğrencilerinin Gelecekten Beklentileri. Elektronik Sosyal Bilimler Dergisi, Vol:7, Issue:26, pp-047-063.

Megaputer. (2020). https://www.megaputer.com/polyanalyst/ adresinden alındı

Nillson, A. (2010). Vocational education and Training- an engine for economic growth and a vehicle for social inclusion. International Journal of Training \& Development, Vol 14,Issue 4.

PolyAnalyst. (2007, Nisan). User Manuel of PolyAnalyst 6.5.

Sen, B., \& Ucar, E. (2012). Evaluating the achievements of computer engineering department of distance education students with data mining methods. Procedia Technology, Vol 1, pp.262-267.

YÖK. (2020)

https://www.yok.gov.tr/Documents/Kurumsal/egitim_ogretim_dairesi/MeslekYuksekokullar\%C4\%B1/05_Asl\%C4\%B1_Gunay.pdf adresinden alındı

YÖK, İ. V. (2020). https://istatistik.yok.gov.tr/ adresinden alındı

Zhang, S., Zhang, C., \& Yang, Q. (2003). Data preparation for data mining. Applied Artificial Intelligence, Vol.173, 75-381. 